\title{
Erratum to: Evolution of a predictive internal model in an embodied and situated agent
}

\author{
Onofrio Gigliotta $\cdot$ Giovanni Pezzulo $\cdot$ \\ Stefano Nolfi
}

Published online: 25 June 2011

(C) Springer-Verlag 2011

Erratum to: Theory Biosci.

DOI 10.1007/s12064-011-0128-x

The third author's name was misspelled in the original publication. The name is correct in this erratum.

The online version of the original article can be found under doi: 10.1007/s12064-011-0128-x.

O. Gigliotta $(\bowtie)$

Natural and Artificial Cognition Laboratory, University

of Naples Federico II, via Porta di Massa 1, 80133 Napoli, Italy

e-mail: onofrio.gigliotta@istc.cnr.it

G. Pezzulo

Istituto di Linguistica Computazionale "Antonio Zampolli",

Via Giuseppe Moruzzi 1, 56124 Pisa, Italy

e-mail: giovanni.pezzulo@istc.cnr.it

S. Nolfi

Institute of Cognitive Sciences and Technologies, CNR,

via San Martino della Battaglia 44, 00185 Rome, Italy

e-mail: stefano.nolfi@istc.cnr.it 